\title{
Prenatal Intra-Amniotic Endotoxin Induces Fetal Gut and Lung Immune Responses and Postnatal Systemic Inflammation in Preterm Pigs
}

\author{
Duc Ninh Nguyen, ${ }^{*}$ Thomas Thymann, ${ }^{*}$ Sandra K. Goericke-Pesch, ${ }^{\dagger}$ Shuqiang Ren, ${ }^{*}$ Wei Wei, ${ }^{*}$ Kerstin Skovgaard,

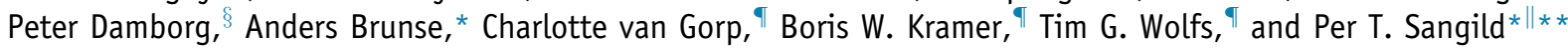

\begin{abstract}
From the Section for Comparative Pediatrics and Nutrition,* Department of Veterinary and Animal Sciences, the Section for Veterinary Reproduction and Obstetrics, ${ }^{\dagger}$ Department of Veterinary Clinical Sciences, and the Department of Veterinary Disease Biology, ${ }^{\S}$ University of Copenhagen, Frederiksberg, Denmark; the Department of Biotechnology and Biomedicine, ${ }^{\ddagger}$ Technical University of Denmark, Lyngby, Denmark; the Department of Pediatrics, ${ }^{\circledR}$ School of Oncology and Developmental Biology, Maastricht University, Maastricht, the Netherlands; the Department of Pediatrics and Adolescent Medicine,"

Rigshospitalet, Copenhagen, Denmark; and the Department of Pediatrics, ** Odense University Hospital, Odense, Denmark
\end{abstract}

\author{
Accepted for publication \\ July $5,2018$. \\ Address correspondence to \\ Per T. Sangild, Ph.D., D.M.Sc., \\ D.V.Sc., Section of \\ Comparative Pediatrics and \\ Nutrition, Department of \\ Veterinary Clinical and Animal \\ Sciences, University of \\ Copenhagen, Dyrlægevej 68 , \\ DK-1870 Frederiksberg C, \\ Denmark. E-mail: pts@sund. \\ ku.dk.
}

\begin{abstract}
Prenatal inflammation is a major risk for preterm birth and neonatal morbidity, but its effects on postnatal immunity and organ functions remain unclear. Using preterm pigs as a model for preterm infants, we investigated whether prenatal intra-amniotic (IA) inflammation modulates postnatal systemic immune status and organ functions. Preterm pigs exposed to IA lipopolysaccharide (LPS) for 3 days were compared with controls at birth and postnatal day 5 after formula feeding. IA LPS induced mild chorioamnionitis but extensive intra-amniotic inflammation. There were minor systemic effects at birth (increased blood neutrophil counts), but a few days later, prenatal LPS induced delayed neonatal arousal, systemic inflammation (increased blood leukocytes, plasma cytokines, and splenic bacterial counts), altered serum biochemistry (lower albumin and cholesterol and higher iron and glucose values), and increased urinary protein and sodium excretion. In the gut and lungs, IA LPS-induced inflammatory responses were observed mainly at birth (increased LPS, CXCL8, and IL-1 $\beta$ levels and myeloperoxidasepositive cell density, multiple increases in innate immune gene expressions, and reduced villus heights), but not on postnatal day 5 (except elevated lung CXCL8 and diarrhea symptoms). Finally, IA LPS did not affect postnatal gut brush-border enzymes, hexose absorption, permeability, or sensitivity to necrotizing enterocolitis on day 5. Short-term IA LPS exposure predisposes preterm pigs to postnatal systemic inflammation after acute fetal gut and lung inflammatory responses. (Am J Pathol 2018, 188: 2629-2643; https://doi.org/10.1016/j.ajpath.2018.07.020)
\end{abstract}

Every year, 15 million infants are born preterm $(<37$ weeks of gestation), and preterm birth is one of the most common causes of neonatal mortality. ${ }^{1}$ Preterm births are often associated with chorioamnionitis, the fetal membrane inflammation. $^{2,3}$ Bacterial invasion of the uterine cavity is the most common infection route, with frequent detection of low virulent Ureaplasma species. ${ }^{4}$ This exposes the fetus to inflammatory agents via direct contact with amniotic fluid or placental-fetal circulation. ${ }^{4}$ Chorioamnionitis is a risk factor for neonatal early-onset sepsis, ${ }^{5}$ necrotizing enterocolitis (NEC), ${ }^{6,7}$ and neurodevelopmental disorders. ${ }^{1}$ Preterm infants may receive formula during the first weeks of life, because of insufficient supply of mother's own milk or donor milk, and this may increase the rate of infection and NEC 2- and 10-fold, respectively. ${ }^{8-10}$ The combination of chorioamnionitis and formula feeding after preterm birth may be highly detrimental for preterm infants, but few studies have investigated the consequences of these combined events.

Supported by the Center of Arla Foods for Health STIMMUNE project (P.T.S. and D.N.N.); and the Innovation Foundation Denmark NEOCOL project (P.T.S.).

Disclosures: None declared. 
In humans, histologic chorioamnionitis exerts specific features of leukocyte infiltration in fetal membranes and is often associated with elevated inflammatory cytokines in amniotic fluid and umbilical cord blood. ${ }^{11,12}$ Studies in fetal lambs and macaques suggest chorioamnionitis-induced multiple fetal organ injuries. ${ }^{4}$ In such experimental models, bacteria or bacterial components [eg, lipopolysaccharide (LPS)] can be administered via the maternal intraamniotic (IA), intracervical, intrauterine, i.p., or i.v. routes. ${ }^{13,14}$ Most of these injection routes (except IA) induce strong maternal and fetal systemic inflammation, whereas human chorioamnionitis often shows more moderate fetal inflammatory responses. ${ }^{15,16}$ Most likely, animal models using IA injection to expose the fetus to inflammatory factors best reflect the conditions in human chorioamnionitis. Inflammatory agents and cytokines in the amniotic fluid are thought to initially interact with fetal epithelial surfaces, including the gut, lung, and skin, to elicit local tissue inflammation before spreading inflammatory signals to the circulation and internal organs. ${ }^{17,18}$ In pigs, IA LPS or Gram-negative bacterial exposure elevates amniotic fluid cytokines and causes fetal lung inflammation with neutrophil/macrophage infiltration. ${ }^{19,20}$ In lambs, both acute and chronic IA exposure (2 to 14 days) to bacteria, fungi, or LPS induces chorioamnionitis and fetal gut inflammation via mucosal immune cell infiltration ${ }^{21-24}$ or modulation of toll-like receptor (TLR) signaling. ${ }^{25}$ In rhesus macaques, IA exposure to LPS or Ureaplasma induces fetal systemic inflammation via increased density of interferon$\gamma$-producing T cells and reduced systemic regulatory T-cell proportions. ${ }^{26,27}$ It is also noteworthy that cord blood monocytes from both IA LPS-exposed fetal sheep and preterm infants are unresponsive to challenge with TLR agonists, ${ }^{28-30}$ suggesting increased susceptibility to neonatal sepsis after preterm birth, especially in those with prenatal inflammation.

Chorioamnionitis is considered a risk factor for neonatal sepsis and NEC in preterm infants, but the causality remains difficult to elucidate from human studies alone because chorioamnionitis is often associated with preterm birth, the main predisposing factor for these complications. ${ }^{31}$ No experimental studies have demonstrated if inflammationinduced fetal organ injuries persist after preterm birth when animals are provided nutrition and colonized with bacteria along the gut, lung, and skin epithelia. Possibly, prenatal inflammation, combined with improper bacterial colonization and a suboptimal diet (formula feeding), may further increase the risk of sepsis and NEC.

Preterm pigs show many of the clinical signs in very preterm infants, including various organ immaturities and high susceptibilities to NEC and infection. ${ }^{32}$ Like in infants, NEC in preterm pigs is highly diet and colonization dependent, ${ }^{33}$ but the effects of prenatal factors, which predispose to preterm birth, are unknown. We hypothesized that short-term exposure to LPS injected into the amniotic fluid induces mild chorioamnionitis and fetal inflammation that predisposes preterm neonates to postnatal systemic inflammation and multiorgan injuries. After IA LPS injection, preterm pigs were investigated at birth and after 5 days of formula feeding, using a novel model of fetal inflammation coupled with studies into postnatal development.

\section{Materials and Methods}

\section{Preterm Pig Model of IA Inflammation}

All fetal surgery and piglet procedures were approved by the Danish National Committee of Animal Experimentation. Three pregnant sows (large white $\times$ Danish Landrace $\times$ Duroc, 20 to 23 fetuses per sow) underwent laparotomy at day 103 of gestation (term at day $117 \pm 2$ ). For each litter, a group of the fetuses received an IA dose of $1 \mathrm{mg}$ LPS/fetus (Escherichia coli 055:B5; Sigma-Aldrich, St. Louis, MO; LPS group, $n=37$ ) into the amniotic fluid in the area close to their mouth, and the remaining fetuses received saline or no injection [control (CON) group, $n=32,16$ in each subgroup; no differences were found in all measured amniotic and tissue parameters between saline and no injection subgroups]. Preterm piglets were delivered at day 106 of gestation ( 3 days after injection) by cesarean section. For each treatment, piglets were randomized according to birth weight and sex into two subgroups: one subgroup was euthanized for tissue collection immediately after birth to characterize LPS effects in utero, and the other subgroup was euthanized on postnatal day 5 to characterize postnatal effects of IA LPS. Newborn piglets from the postnatal group were immediately transferred to warm incubators $\left(37^{\circ} \mathrm{C}\right)$, where they received supplemental oxygen $(0.5$ to $2 \mathrm{~L} / \mathrm{min}$ ute) for the first 24 hours. Each pig was fitted with a vascular catheter (4F; Portex, Kent, UK) via the umbilical artery for provision of parenteral nutrition and an orogastric catheter (6F; Portex) for enteral nutrition. ${ }^{34}$ During the first 24 hours after birth, pigs received $16 \mathrm{~mL} / \mathrm{kg}$ maternal plasma via the umbilical catheter for provision of passive immunity. Neonatal pigs received parenteral nutrition (Kabiven, $3210 \mathrm{~kJ} / \mathrm{L}$, modified to meet piglet nutrient requirement $^{33}$; Fresenius Kabi, Uppsala, Sweden) of 2 to $4 \mathrm{~mL} / \mathrm{kg}$ per hour and a gradually increasing amount of enteral nutrition (3 to $15 \mathrm{~mL} / \mathrm{kg}$ per 3 hours) with formula for 5 days. The formula composition included $75 \mathrm{~g} / \mathrm{L}$ Liquigen MCT (Nutricia, Allerød, Denmark), 80 g/L Pepdite (Nutricia), and $70 \mathrm{~g}$ Lacprodan DI-9224 (Arla Foods Ingredients, Viby, Denmark), equivalent to $960 \mathrm{kcal} / \mathrm{L}$ $(24 \%, 36 \%$, and $40 \%$ of energy from protein, fat, and carbohydrate, respectively). Formula feeding in preterm piglets has been shown to spontaneously induce NEC with an incidence of $40 \%$ to $60 \%{ }^{33,35}$

Clinical conditions and fecal characteristics were evaluated twice daily. Fecal matter was scored as follows: 0, no stool; 1, meconium or firm feces; 2 , pasty feces; 3 , diarrhea with isolated droplets of watery feces; 4 , moderate diarrhea 
with more droplets or larger areas of fecal matter; and 5, severe diarrhea with extensive watery feces. ${ }^{36}$ The time from birth to the first sign of standing and walking was recorded. At euthanasia (day 1 or 5), four gastrointestinal regions (proximal, middle, and distal small intestine and colon) were evaluated macroscopically for NEC-like lesions using a scoring system (1 to 6), as previously described ${ }^{34}: 1$, normal appearance; 2, mild hyperemia and/or edema; 3, extensive hyperemia, edema, and local hemorrhage; 4, extensive hemorrhage and/or pneumatosis intestinalis; 5, hemorrhage with local necrosis; and 6, severe hemorrhage and necrosis. Pigs with scores of $\geq 3$ in any of the four regions were designated as having NEC. Fecal and NEC scoring were performed by personnel who were not involved in the study. Brains were collected at euthanasia, and left cerebral hemispheres were weighed and dehydrated for 14 days at $50^{\circ} \mathrm{C}$, followed by determination of dried weight for water content estimation. Tissues were snap frozen and stored at $-80^{\circ} \mathrm{C}$ for future analyses or fixed in paraformaldehyde $4 \%$ for histology. Gut brush-border enzymatic activities were measured by spectrophotometry, as previously described. ${ }^{33}$

\section{In Vivo Tests}

For pigs reared until day 5, three in vivo tests were performed. Absorptive function was evaluated on day 3 by plasma galactose measurement 20 minutes after giving an enteral bolus of $15 \mathrm{~mL} / \mathrm{kg}$ of a $5 \%$ galactose solution. Three hours before euthanasia, an intestinal permeability test was performed by giving an enteral bolus of $15 \mathrm{~mL} / \mathrm{kg}$ of a $5 \%$ lactulose and 5\% mannitol solution (Sigma-Aldrich), followed by measurement of urinary lactulose and mannitol at euthanasia. To assess the permeability of the blood-cerebrospinal fluid barrier, a systemic bolus of raffinose solution $(4 \mathrm{~mL} / \mathrm{kg}$ of $10 \%$ raffinose; Sigma-Aldrich) was provided via the umbilical catheter 30 minutes before euthanasia. The ratio of plasma/cerebrospinal fluid raffinose levels at euthanasia was determined by mass spectrometry using an Acquity ultraperformance liquid chromatography-triple quadrupole mass spectrometer equipped with an HSS T3 C18 column (all from Waters, Milford, MA) with external standards of raffinose.

\section{Amniotic Fluid and Blood Cell Subsets and Function}

During the cesarean section, amniotic fluid (AF) was sampled from the amniotic sac by a $16 \mathrm{G}$ needle and aliquoted for manual counting of total leukocytes under a microscope. Arterial blood was collected at birth (umbilical cord) and day 3 and day 5 before euthanasia for analysis of blood leukocyte counts (Advia 2120i Hematology System; Siemens, Erlangen, Germany) and neutrophil phagocytosis function (using pHrodo Red E. coli Bioparticles Phagocytosis Kit for flow cytometry), as described previously. ${ }^{37}$ Centrifuged $\mathrm{AF}\left(1500 \times g, 4^{\circ} \mathrm{C}\right.$ for 10 minutes $)$ and plasma from euthanasia just after birth (day 1) and on day 5 were stored at $-80^{\circ} \mathrm{C}$ for further analysis.

Blood and Urine Biochemistry and AF, Plasma, Lung, and Gut Cytokines and Mediators

Biochemical analyses, including total protein, albumin, cholesterol, creatinine, urea, liver enzymes, and electrolytes, on serum and urine were performed at euthanasia and on days 1 and 5 using an Advia 1800 Chemistry System (Siemens). Lung and gut (proximal and distal small intestine) tissues were homogenized, and homogenates were stored at $-80^{\circ} \mathrm{C}$. Tissue homogenates, $\mathrm{AF}$, and plasma were analyzed for CXCL8, IL-6, IL-1 $\beta$, tumor necrosis factor- $\alpha$, IL-10, and intestinal fatty acid binding protein by enzymelinked immunosorbent assay (R\&D Systems, Abingdon, UK). Plasma and distal intestinal tissues were also analyzed for endotoxin levels using the LAL chromogenic end point assay (Hycult Biotech, Uden, the Netherlands).

\section{Liver and Splenic Bacteriology and Tissue Histology}

Liver and spleen at euthanasia were aseptically sampled, homogenized, and cultured in 10-fold dilutions on calf blood agar at $37^{\circ} \mathrm{C}$ for 24 hours, followed by bacterial colony counting, subculturing, and identification of pure isolates by matrix-assisted laser desorption ionization timeof-life analysis, as previously described. ${ }^{38}$

Fixed tissues of chorioamnion and small intestinal tissues were embedded in paraffin, sectioned, and stained with hematoxylin and eosin, as previously described. ${ }^{34}$ Villus height and crypt depth from representative sections of three intestinal regions were measured using ImageJ software version 1.50i (NIH, Bethesda, MD; https://imagej.nih. gov/ij). Chorioamnion sections were evaluated by a pathologist (T.T.) who was blinded to treatment groups for immune cell infiltration using a scoring system ${ }^{39,40}: 0$, no or few inflammatory cells (no chorioamnionitis); 1, significant amounts of inflammatory cells restricted to chorion (stage 1 of chorioamnionitis); 2, both chorion and amnion (stage 2); or 3, necrotizing amniotic epithelial cells (stage 3). Distal intestinal and colon sections were also stained with Alcian Blue and periodic acid-Schiff for quantification of mucin-containing goblet cell density, measured as goblet cell area relative to total area of the tunica mucosa. ${ }^{34,35}$

Distal small intestinal sections were also stained for CD3 and Foxp3, as previously described. ${ }^{23}$ Briefly, CD3 was stained by anti-CD3 antibody, followed by porcine antirabbit biotin-conjugated secondary antibody (both from Dako Denmark, Glostrup, Denmark), and visualized with nickel-diaminobenzidine (Sigma-Aldrich). Foxp3 was stained by anti-Foxp3 antibody (Abcam, Cambridge, UK), followed by goat anti-rabbit peroxidase-conjugated secondary antibody (Jackson, West Brove, PA), and visualized with 3-amino-9-ethylcarbazole (Sigma-Aldrich). Nuclei were counterstained with nuclear fast red (CD3) or 
Table 1 Gene Names and Primer Sequences for Gut Gene Analysis

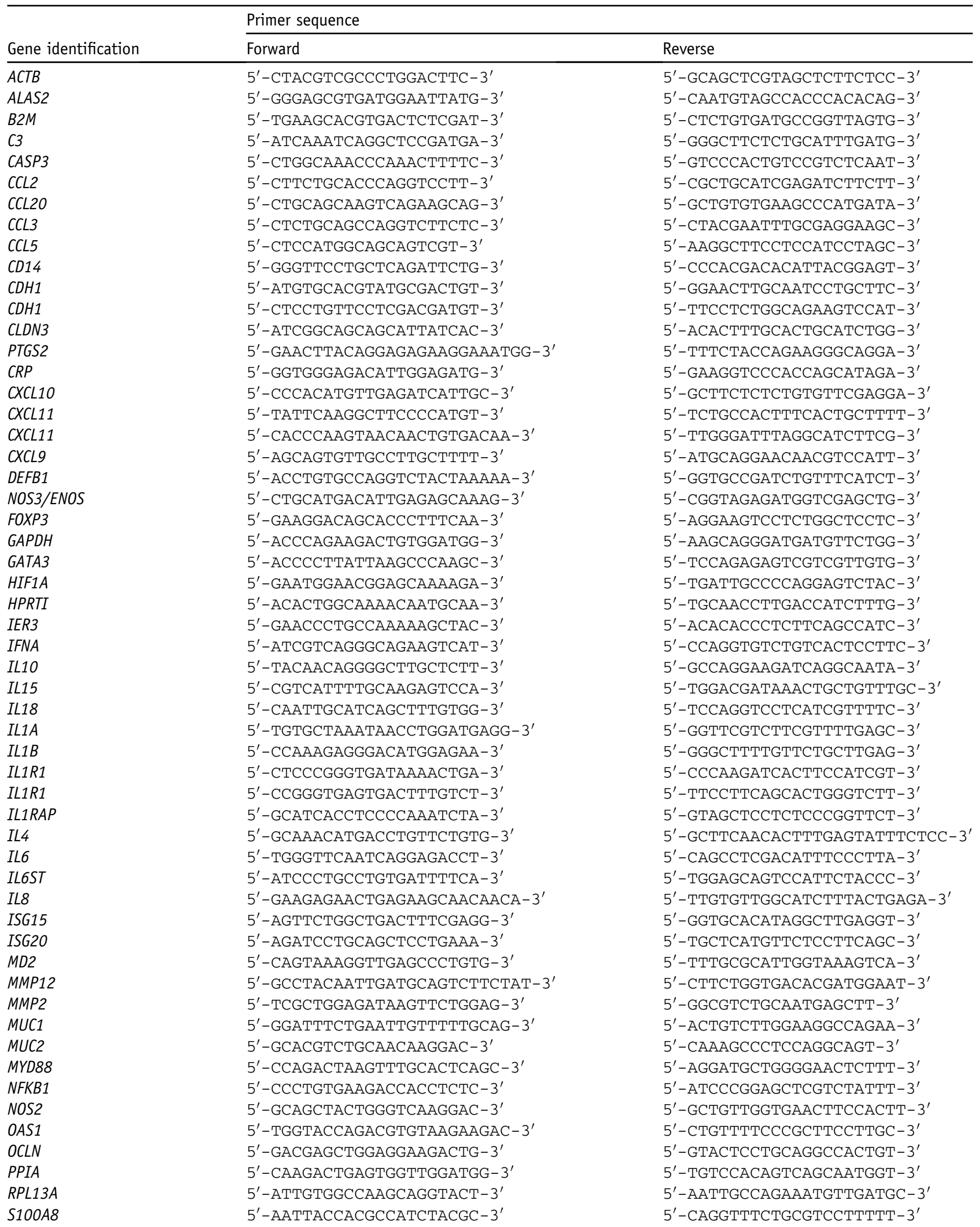

(table continues) 
Table 1 (continued)

\begin{tabular}{|c|c|c|}
\hline \multirow[b]{2}{*}{ Gene identification } & \multicolumn{2}{|l|}{ Primer sequence } \\
\hline & Forward & Reverse \\
\hline STAT1 & $5^{\prime}-\mathrm{CCTTGCAGAATAGAGAACATGATAC}-3^{\prime}$ & 5'-CСTTTCTCTTGTTGTCAAGCATT-3' \\
\hline TBP & 5'-ACGTTCGGTTTAGGTTGCAG-3' & $5^{\prime}$-CAGGAACGCTCTGGAGTTCT-3' \\
\hline YWHAE & 5'-GCTGCTGGTGATGATAAGAAGG-3' & $5^{\prime}$-AGTTAAGGGCCAGACCCAAT- $3^{\prime}$ \\
\hline$T G F B$ & 5'-GCAAGGTCCTGGCTCTGTA-3' & $5^{\prime}-$ TAGTACACGATGGGCAGTGG- $3^{\prime}$ \\
\hline TNFAIP3 & $5^{\prime}$-CCCAGCTTTCTCTCATGGAC-3' & 5'-TTGGTTCTTCTGCCGTCTCT-3' \\
\hline TRAF6 & $5^{\prime}-\mathrm{CTGCCATGAAAAGATGCAGA-3^{ \prime }}$ & $5^{\prime}$-GCGACTGGGTATTCTCTTGC- $3^{\prime}$ \\
\hline VEGFA & $5^{\prime}$-CGAAGGTCTGGAGTGTGTGC-3' & 5'-TCTCTCCTATGTGCTGGCCT-3' \\
\hline 201 & 5'-ATGACTCCTGACGGTTGGTC-3' & 5'-TGCCAGGTTTTAGGATCACC-3' \\
\hline
\end{tabular}

hematoxylin (Foxp3). Stained slides were scanned using Ventana IScan (Ventana Medical System, Inc., Tucson, $\mathrm{AZ}$ ), and the number of positive cells per $\mathrm{mm}^{2}$ of mucosal surface area was calculated using Qwin Pro software version 3.4.0 (Leica Microsystems, Wetzlar, Germany).

Myeloperoxidase (MPO) in the lungs and distal small intestine was also stained by rabbit anti-human MPO antibody, followed by anti-rabbit biotin-conjugated secondary antibody (Dako Denmark), and visualized with nickeldiaminobenzidine. CD3 in the lungs was stained by mouse anti-pig CD3 antibody (SouthernBiotech, Birmingham, AL) and visualized with Fast Red (KemEnTec, Taastrup, Denmark). Hematoxylin was used as counterstaining. Slides were scanned using Zeiss Axio Scan Z1 (Zeiss, Oberkochen, Germany), and positive stained area fraction in the total tissue area was quantified using ImageJ.

\section{Gut Gene Expression}

Total RNA from the distal small intestine ( $n=8$ to 10 in each group) was extracted using RNeasy MiniKit, and cDNA was synthesized using QuantiTect Reverse Transcription Kit (Qiagen, Copenhagen, Denmark). Primers (Table 1) were designed flanking intron-exon borders using Primer3 version 0.4.0 (bioinfo.ut.ee/primer3-0.4.0). Real-time quantitative PCR (35 cycles) of preamplified cDNA (20 cycles) was conducted using 96.96 Dynamic Array Integrated Fluidic Circuits (Fluidigm, San Francisco, CA) for 96 preamplified samples and 96 targets related to gut immunity and barrier functions, as previously described. ${ }^{41}$ Two cDNA syntheses were prepared for each RNA sample. Expression data (quantification cycle) were obtained by Fluidigm Real-Time PCR Analysis software version 4.3.1 (Fluidigm) and preprocessed in GenEx (MultiD, Gothenburg, Sweden), with PCR efficiency correction for each primer assay and normalization to the most stable reference genes (GAPDH, HPRTI2, RPL13A, PPIA, TBP, B2M, and TBPI) identified by GeNorm $^{42}$ and NormFinder. ${ }^{43}$ For each primer assay, the mean relative expression in CON pigs euthanized on day 1 was set to 1 , and other groups were scaled accordingly.

\section{Statistical Analysis and Bioinformatics}

Statistics were performed using JMP 13.0 (SAS Institute, Cary, NC). All continuous outcomes, except for temporal blood data, were compared between CON and LPS pigs on day 1 and on day 5 by linear models with treatment (LPS or CON), litter, and sex as fixed factors. Temporal blood data were fitted into linear mixed models, with treatment, time, sex, and litter as fixed factors (including treatment and time interaction) and pig code as a random factor. Treatment comparisons at each time point were performed by post hoc analyses using test slices. Data transformation (log or square root) was performed when necessary. Noncontinuous and nonnormally distributed outcomes were analyzed by the nonparameteric $U$-test. Values were means $\pm \mathrm{SEM}$, and $P<0.05$ was regarded as statistically significant.

\section{Results}

\section{Prenatal LPS Exposure Induces Intra-Amniotic Inflammation}

After IA LPS injection until the planned cesarean section 3 days later, the sows showed no signs of maternal infection. Relative to CON, LPS fetuses had extensive IA inflammation with approximately 5- to 20-fold elevated levels of AF leukocytes and cytokines CXCL8, IL-6, IL-1 $\beta$, tumor necrosis factor- $\alpha$, and IL-10 (all $P<0.01$ or $P<0.001$ ) (Figure 1, A and B). IA LPS also elevated numbers of infiltrated inflammatory cells in the chorioamnion $(P<0.05)$ (Figure $1, \mathrm{C}-\mathrm{F})$. However, only a mild induction of histologic chorioamnionitis was observed, with inflammatory cell infiltration restricted mainly to the chorion, whereas only a small proportion of LPS fetuses had inflammatory cell spreading to the amnion (15\%; score, 2$)$ or necrotizing amniotic epithelial cells (15\%; score, 3 ).

\section{Clinical Evaluation and Organ Weights}

At delivery, 5 of 37 LPS-exposed fetuses were found dead in utero, compared with no deaths occurring for $\mathrm{CON}$ 

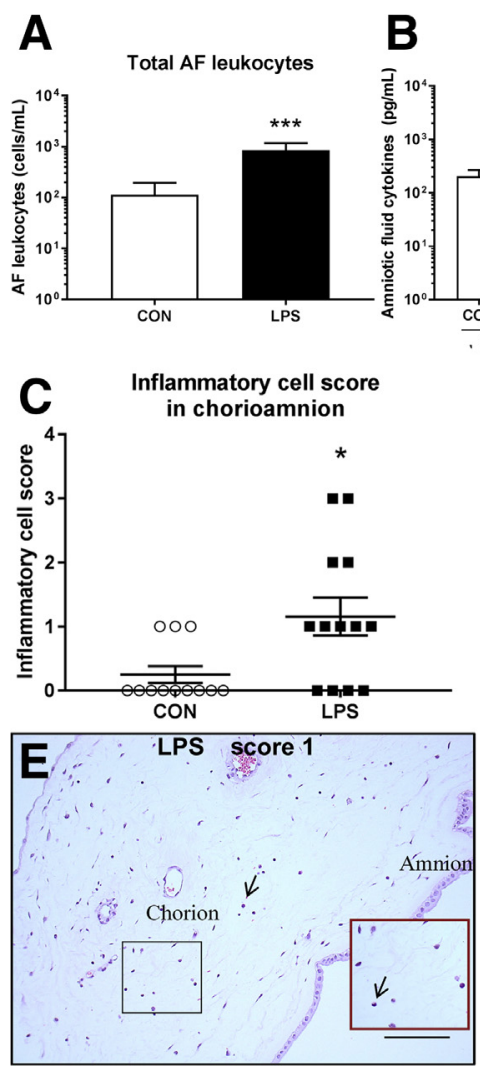
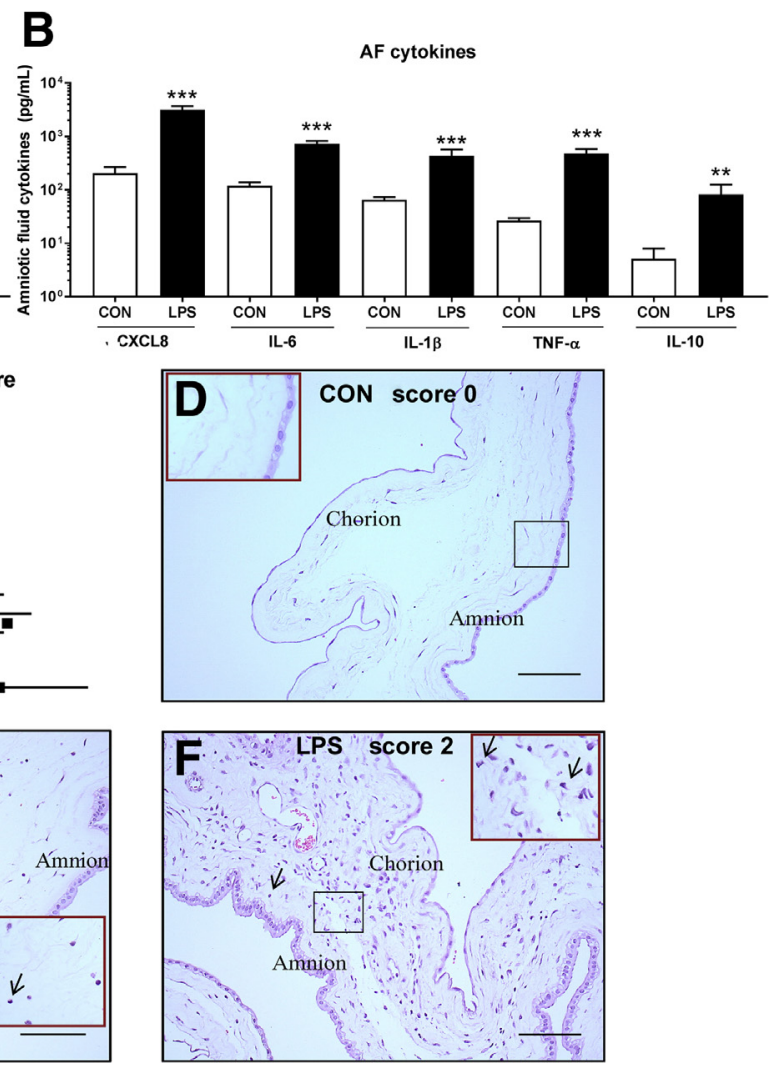

Figure 1 Effects of intra-amniotic lipopolysaccharide (LPS) exposure on intra-amniotic inflammation and chorioamnionitis in preterm pigs. A and B: Amniotic fluid (AF) leukocytes (A) and cytokines (B). Linear models with treatment and litter as fixed factors were used for statistics. C-F: Inflammatory cell infiltration in fetal membranes, with arrows indicating inflammatory cells in amnion and/or chorion. C: Values were compared using nonparametric U-test. Boxed areas are shown at higher magnification in the insets. Data are expressed as means \pm SEM (A and $\mathbf{B}) . n=24$ per group (A); $n=24$ to 29 per group (B); $n=12$ CON (C-F); $n=13$ LPS (C-F). ${ }^{*} P<0.05,{ }^{* *} P<0.01$, and ${ }^{* * *} P<0.001$ versus CON. Scale bars $=100 \mu \mathrm{m}(\mathbf{D}-\mathbf{F})$. CON, control; TNF- $\alpha$, tumor necrosis factor- $\alpha$. fetuses $(P=0.06)$. For characterization of LPS effects in utero, 12 CON and 13 LPS pigs were euthanized immediately after birth (day 1). Among the pigs reared and fed after birth, five CON and three LPS pigs died within the first 48 hours because of respiratory distress and were excluded from the final analyses. A total of $15 \mathrm{CON}$ and $15 \mathrm{LPS}$ pigs survived until day 5 when tissues were collected after euthanasia. No significant differences in organ weights between the two treatments at each euthanasia time point were observed, except the decrease in relative kidney weight in LPS versus CON pigs on day $5(P<0.05)$ (Supplemental Table S1). Five-day-old LPS pigs had a tendency to increased brain hydration $(P=0.05)$ and relative cerebellum weight $(P=0.10)$ (Supplemental Figure S1, A and $\mathrm{B})$. The raffinose ratio in cerebrospinal fluid and plasma, used to determine the permeability of blood-cerebrospinal fluid barrier, showed no difference between CON and LPS pigs on day 5, but was higher in pigs with NEC lesions versus pigs without NEC $(P<0.05)$ (Supplemental Figure S1, C and D).

\section{Effects of Prenatal LPS Exposure on the Fetal and Neonatal Lungs}

CXCL8 and IL-1 $\beta$ levels were highly elevated in the lungs of LPS versus CON fetuses (13- and 6-fold, respectively; $P<0.001$ ), whereas on postnatal day 5, only lung CXCL8 levels were still higher in LPS versus CON pigs (1.6-fold, $P<0.05$ ) (Figure 2, A and B). No differences in lung IL-6 levels between treatments were detected (Figure 2C). Both CXCL8 and IL-1 $\beta$ levels in LPS pigs were significantly lower on day 5 versus day $1(P<0.001)$ (Figure 2 , A and B), indicating extensive LPS-induced lung inflammation before birth that remained present but was less severe on postnatal day 5. The area of $\mathrm{MPO}^{+}$cells (marker of neutrophil/macrophage infiltration) showed $9 \%$ to $17 \%$ of total tissue area, with a twofold higher value in LPS versus CON pigs $(P<0.05)$ on day 1 but no difference between the two treatments on day 5 (Figure 2, D-F). On the other hand, the area of $\mathrm{CD}^{+}$cells (markers of $\mathrm{T}$ lymphocytes) was much lower than $\mathrm{MPO}^{+}$cells, with $0.15 \%$ to $0.55 \%$ of total tissue area and no difference between CON and LPS groups, neither on day 1 nor day 5 (Figure 2, G-I).

\section{Effects of Prenatal LPS on the Fetal and Neonatal Gut}

On day 1 , relative to CON, LPS pigs had higher distal intestinal CXCL8 and IL-1 $\beta$ levels $(P<0.05$ or $P<0.01)$ (Figure 3, A and B), but these cytokines did not differ between the two groups on day 5. Plasma intestinal fatty acid binding protein levels were not different between the two treatments on day 1 , but they were numerically higher in LPS versus CON pigs on day 5 despite being insignificant (Figure 3C). 

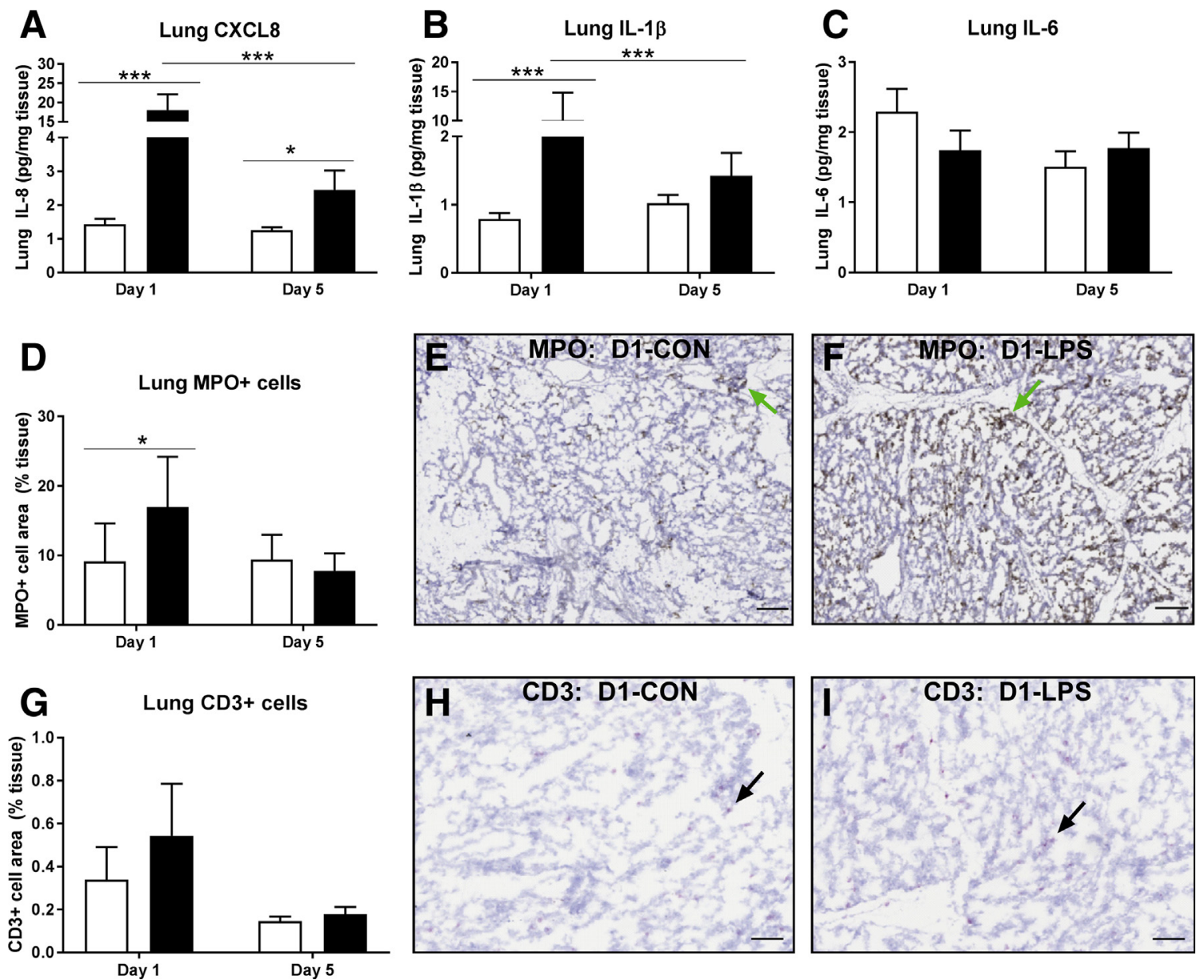

Figure 2 Effects of intra-amniotic lipopolysaccharide (LPS, black bars) exposure on fetal (day 1) and postnatal (day 5) lung inflammation in preterm pigs. Inflammatory cytokines $(\mathbf{A}-\mathbf{C})$, myeloperoxidase-positive $\left(\mathrm{MPO}^{+}\right)$-stained cells (brown; green arrows; $\mathbf{D}-\mathbf{F}$ ), and $\mathrm{CD}^{+}$-stained cells (pink; black arrows; G-I) in lung tissues of control (CON, white bars) and LPS pigs at euthanasia on postnatal days 1 (D1) and 5. Linear models with treatment and litter as fixed factors were used for statistics. Data are expressed as means \pm SEM (A-D and $\mathbf{G}) . n=11$ to 12 day $1(\mathbf{A}-\mathbf{I}) ; n=15$ day $5(\mathbf{A}-\mathbf{I})$. ${ }^{*} P<0.05,{ }^{* * *} P<0.001$. Scale bars: $200 \mu \mathrm{m}$ (E and $\mathbf{F}) ; 100 \mu \mathrm{m}(\mathbf{H}$ and $\mathbf{I})$.

In the distal small intestine, 54 of 76 unique tested genes related to immunity and gut barrier functions passed quality testing on real-time quantitative PCR, with sufficient reaction efficiency and cDNA reproducibility, and 14 genes showed significant $(P<0.05)$ or tendency to differences $(P<0.10)$ between LPS and CON pigs. The expression of multiple genes involved in innate immune response and chemotaxis was elevated in LPS versus CON pigs on day 1 , but not day 5, including TLR2, CD14, ILIB,C3, and CXCL9 (all $P<0.05)$, and $I S G 20(P<0.1)$ (Figure 3D). HIF1A expression, regulating the hypoxia-inducible factor-1 pathway in response to inflammation, tended to be down-regulated in LPS versus CON pigs on both days 1 and $5(P=0.08)$, whereas TLR4 expression was not affected (Figure 3D). ZO1 expression, involved in gut barrier integrity, was lower in LPS versus CON pigs only on day 1. In addition, relative to CON pigs, LPS pigs on both days 1 and 5 showed a tendency to elevated expressions of gut genes involved in immune suppression by regulatory $\mathrm{T}$ cells
(Tregs), including TGFB (day 1) and FOXP3, IL10, and TNFAIP3 (day 5, $P<0.10$ ) (Figure 3D). Expression of gut IL6, which, together with TGFB, regulates type 17 helper T-cell activity, was not altered by IA LPS.

There were limited LPS effects on gut digestive and absorptive functions. Only proximal intestinal sucrase activity among tested brush-border enzymes tended to be lower in LPS versus CON pigs $(P=0.06$ to $P=0.10$, both days 1 and 5), and plasma galactose levels after the galactose bolus and gut permeability were similar between the two treatments (Supplemental Figure S2, A-H). Relative to CON pigs, postnatal LPS pigs had a higher incidence of diarrhea over time $(P<0.05)$ as well as a higher incidence of severe diarrhea $(53 \%$ versus $7 \% ; P<0.05$ ) (Figure 3, $\mathrm{E}$ and F). At euthanasia on day 5, LPS and CON pigs had a similar incidence of macroscopic NEC-like lesions $(9 / 15$ CON versus $6 / 15$ LPS pigs; $P=0.47$ ) and a similar NEC severity score (1.7 to 1.8 in the gut and 2.5 to 3.2 in the colon; $P=0.82$ and $P=0.29$, respectively) (Supplemental 

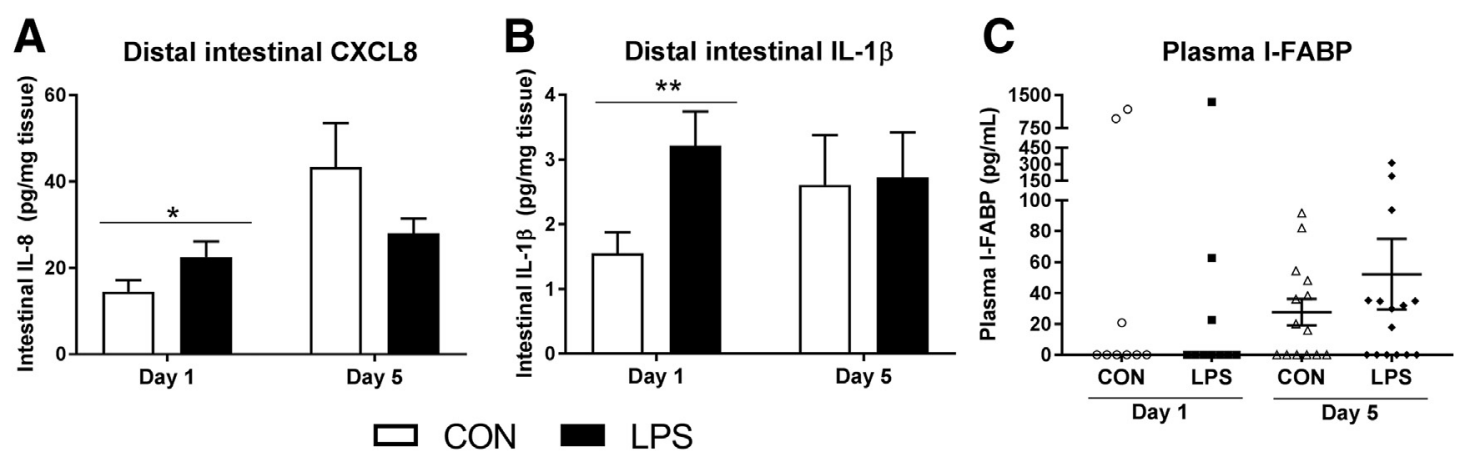

D

Gut immune gene expression

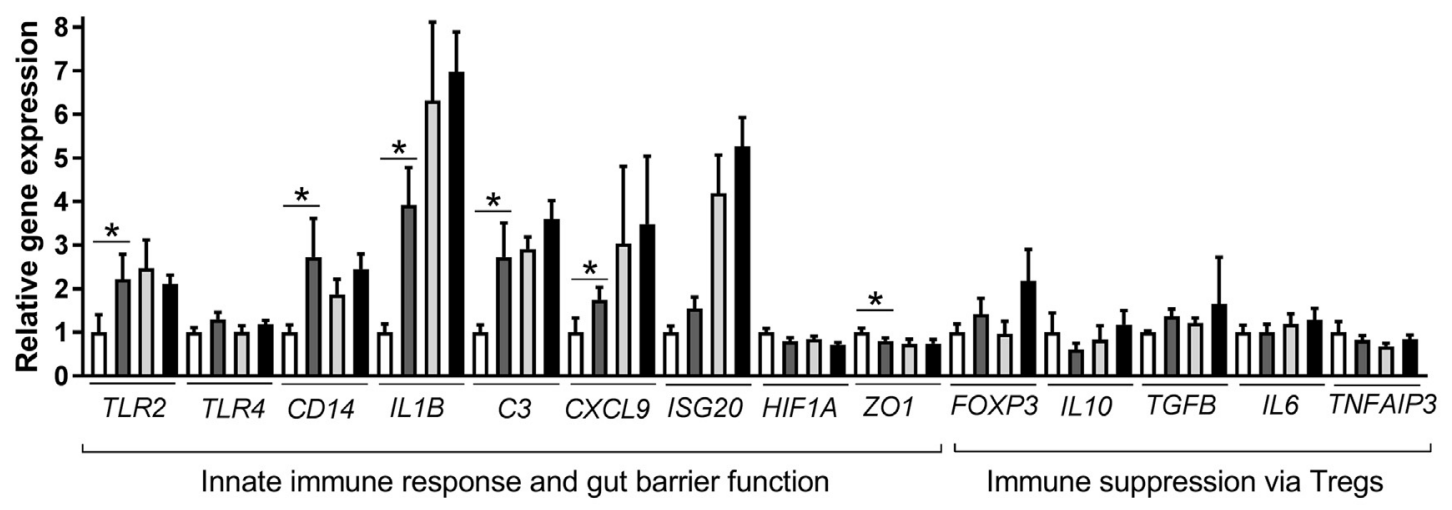

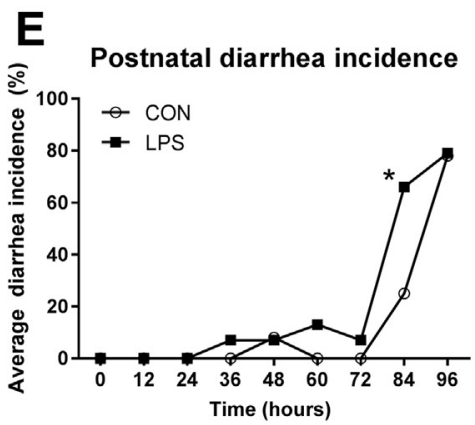
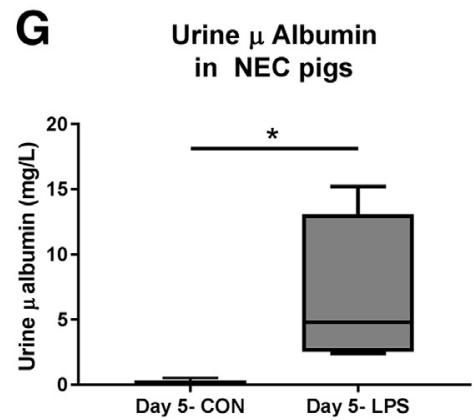

$\mathbf{F}$
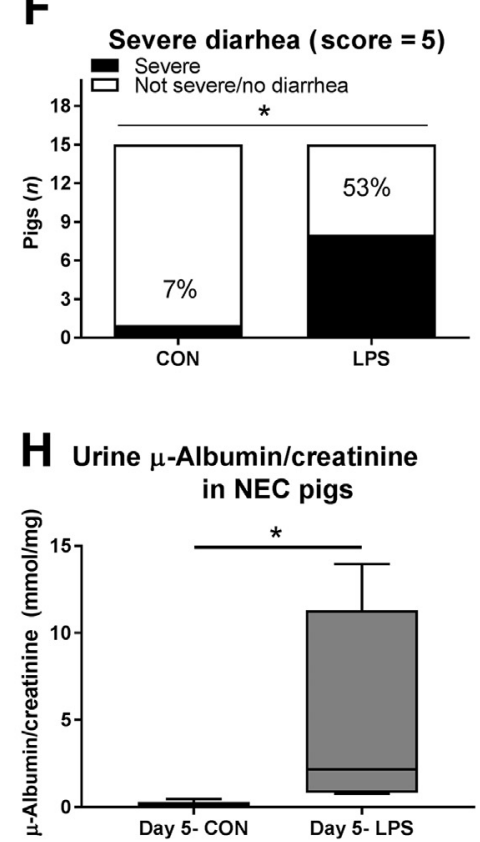

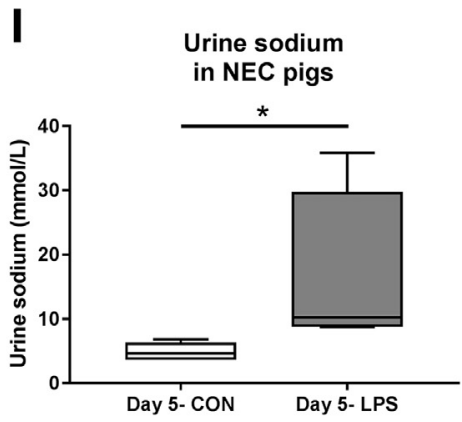

Figure 3 Intra-amniotic lipopolysaccharide (LPS) induces fetal and postnatal gut inflammation and kidney injuries in formula-fed preterm pigs. A-C: Gut cytokines and plasma intestinal fatty acid binding protein (I-FABP). D: Relative expression of genes related to immune regulation and gut barrier function in the distal small intestine; relative expression of genes in control (CON) pigs on day 1, which was assigned an arbitrary unit of 1 . E and F: Postnatal diarrhea incidence and severe diarrhea incidence. A-E: Linear models with treatment and litter as fixed factors (also including time for clinical evaluation as a random factor in E) were used for statistics. F: Values were compared by Fisher exact test. G-I: Urinary $\mu$-albumin, $\mu$-albumin/creatinine ratio, and sodium in necrotizing enterocolitis (NEC) pigs on day 5. G-I: Boxes represent 25th to 75th percentiles, horizontal lines are medians, and whiskers represent minimum and maximum values (U-test). Data are expressed as means or means \pm SEM (A-E). $n=9$ to 11 day 1 (A-C,); $n=15$ day 5 (A-C); $n=8$ to 9 day 1 (D); $n=10$ day $5(\mathbf{D}) ; n=4$ to 5 per group $(\mathbf{G}-\mathbf{I}) .{ }^{*} P<0.05,{ }^{*} P<0.01$. 
Figure S2, I and J), with relatively mild NEC phenotypes and mainly colonic lesions. Representative autopsy images of stomach, small intestine, and colon, with and without NEC, on day 5 are presented in Supplemental Figure S2, K and L. No pigs euthanized immediately after birth (without any feeding, day 1) had any NEC lesions. Among the 5-day-old pigs with NEC diagnosis, the LPS group had increased levels of urinary $\mu$-albumin, $\mu$-albumin/creatinine ratio, and sodium $(P<0.05)$ (Figure $3, \mathrm{G}-\mathrm{I})$, indicating renal dysfunction.

Villus height in the distal small intestine was lower in LPS than CON pigs on day $1(P<0.05)$ but was not different between the two groups on day 5 (Figure 4, $\mathrm{A}-\mathrm{C}$ ). Endotoxin levels in the distal small intestine were markedly higher in LPS versus CON pigs on day 1
$(P<0.01)$ but were similar between the two treatments on day 5 (Figure 4D). This suggests that the fetal gut of LPS pigs was directly exposed to IA LPS, whereas endotoxin detected on postnatal day 5 may mainly reflect levels of colonized Gram-negative bacteria from the environment. Colonic and distal intestinal goblet cell densities were not different between the two treatment groups but were higher on day 1 versus day $5(P<0.05)$ (Figure $4, \mathrm{E}-\mathrm{F})$. In the distal small intestine, $\mathrm{CD}^{+}{ }^{+} \mathrm{T}$-cell infiltration was similar between the two treatments on both days 1 and 5, whereas density of $\mathrm{MPO}^{+}$cells and Foxp $3^{+} \mathrm{T}$ cells was elevated in LPS versus CON pigs on day $1(P<0.05)$ but not on day 5 (Figure 4, G-O). Collectively, the data suggest that IA LPS induced clear innate inflammatory responses at birth, but the LPS effects on the postnatal gut were limited, with
A

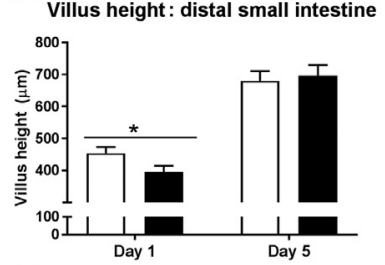

D

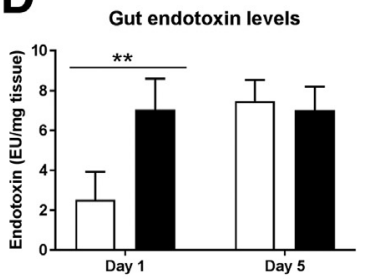

G
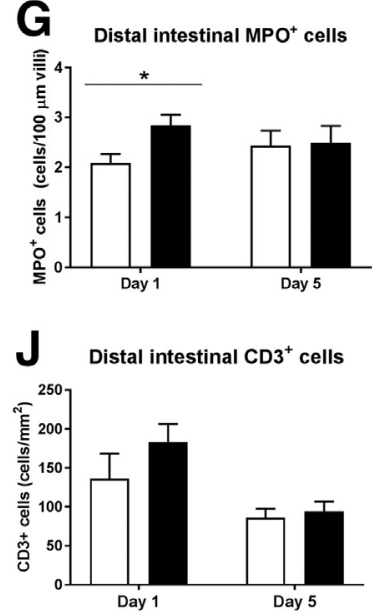

M Distal intestinal Foxp3+ cells

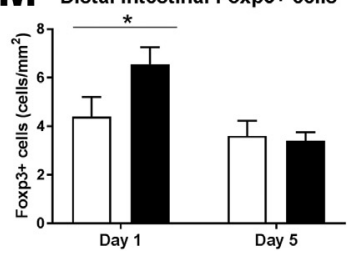

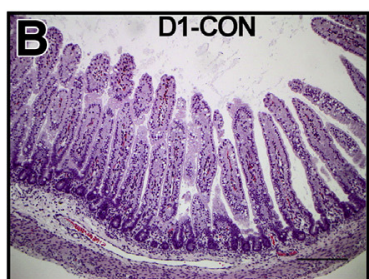
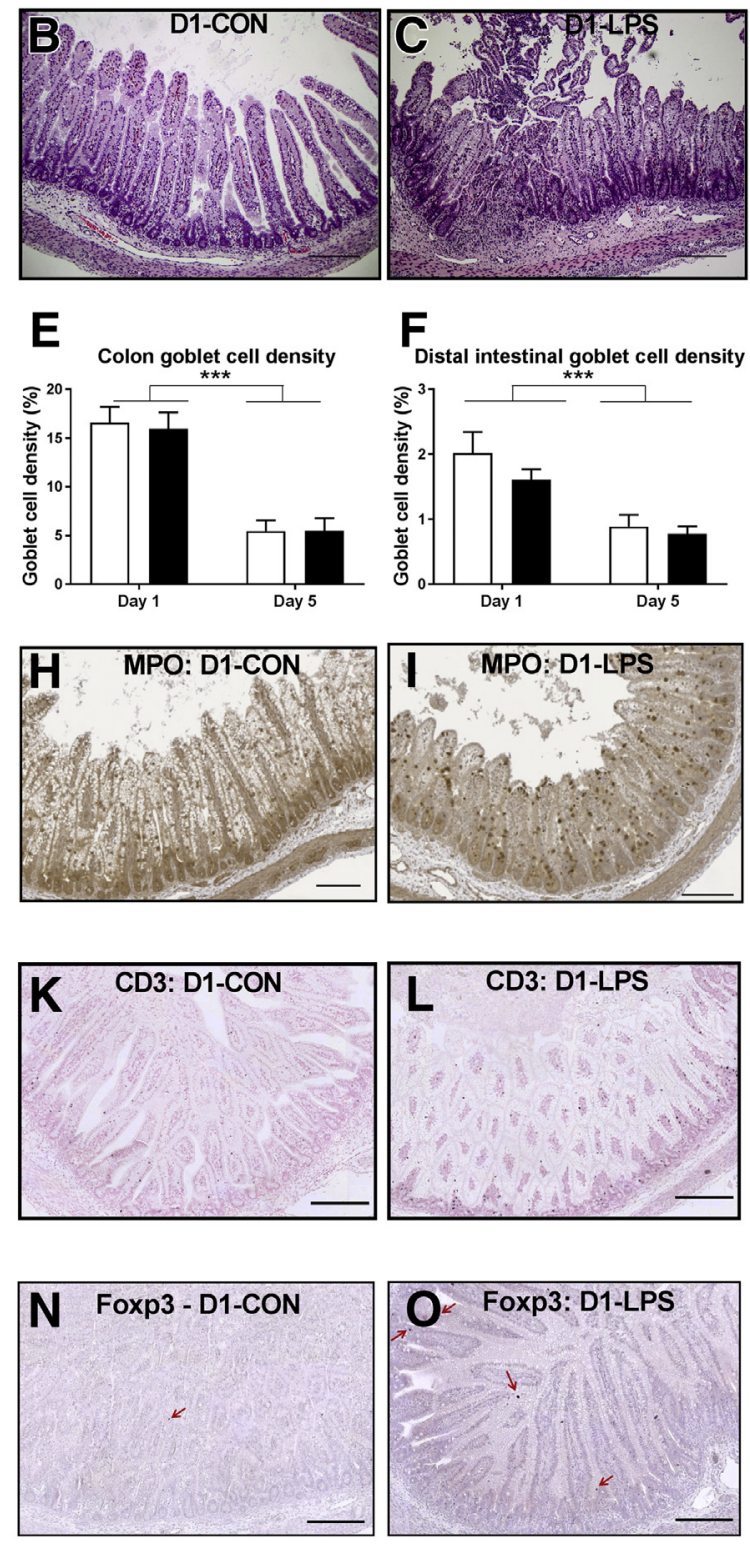
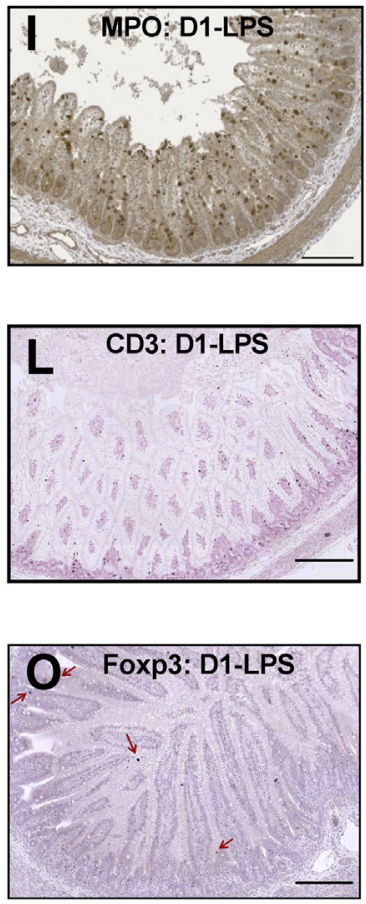

Figure 4 Effects of intra-amniotic lipopolysaccharide (LPS, black bars) inflammation on postnatal gut morphology, goblet cell density, and immune cell infiltration. A-C: Villus and crypt structure in the distal small intestine. D: Endotoxin levels in the distal small intestine. $\mathbf{E}$ and $\mathbf{F}$ : Goblet cell density with blue and violet staining (Alcian Blue and periodic acid-Schiff) in the distal small intestine (F) and colon (E). G-0: Myeloperoxidase (MPO; brown staining; $\mathbf{G}-\mathbf{I}$ ), $\mathrm{CD} 3$ (black staining; $\mathbf{J}-\mathrm{L}$ ), and Foxp3 (black staining; arrows; $\mathbf{M - 0}$ ) in the distal small intestine. Linear models with treatment and litter as fixed factors were used for statistics. Data are expressed as means \pm SEM (A, D-G, J, and $\mathbf{M}) . n=9$ to 15 per group $(\mathbf{A}-\mathbf{M})$. ${ }^{*} P<0.05,{ }^{* *} P<0.01$, and $* * * P<0.001$. Scale bars: $200 \mu \mathrm{m}(\mathbf{B}, \mathbf{C}, \mathbf{H}$, and I); $50 \mu \mathrm{m}(\mathbf{K}, \mathbf{L}, \mathbf{N}$, and $\mathbf{0})$. CON, control (white bars); D1, postnatal day 1 . 
only poorer gut clinical symptoms in LPS versus CON pigs on day 5 .

\section{Prenatal LPS Predisposed to Fetal and Neonatal Systemic Inflammation}

Hematological parameters were similar between CON and LPS groups on day 1 and day 3, with the exception of cord blood neutrophils being higher (1.8-fold) and neutrophil phagocytic capacity (average number of bacteria engulfed by each neutrophil) being lower in LPS versus CON pigs (Figure 5, A-H). In contrast, multiple hematological parameters were elevated in LPS versus CON pigs on postnatal day 5, including total leukocytes, neutrophils, lymphocytes, eosinophils, and basophils (1.3- to 2.7-fold, all $P<0.05$ ). On day 5, the percentage of blood neutrophils exerting phagocytosis decreased in LPS versus CON pigs, whereas phagocytic capacity did not differ between the two treatments despite its decreasing levels over time (Figure 5, $\mathrm{G}$ and $\mathrm{H}$ ). Plasma IL-1 $\beta$ and IL-6 levels did not differ between the two treatments on day 1 but were elevated in LPS versus CON pigs on day 5 (1.8-fold and $P<0.05$ for IL-1 $\beta$ and 1.3-fold and $P=0.07$ for IL-6) (Figure 5, I and J).
The other three measured plasma cytokines (tumor necrosis factor- $\alpha$, CXCL8, and IL-10) did not differ between the two treatments, either on day 1 or on day 5 (Supplemental Figure S3, A-C). Importantly, the serum endotoxin levels were negligible and not different between CON and LPS pigs on both day 1 ( 0.8 to $0.9 \mathrm{EU} / \mathrm{mL})$ and day 5 (1.2 to 2 $\mathrm{EU} / \mathrm{mL}$ ), similar to previously observed levels in the blood of a healthy donor. ${ }^{44}$

Importantly, for those nourished until postnatal day 5, CON pigs were on their feet and walked for the first time approximately 1 day after birth (25.7 and 27.4 hours, respectively). In contrast, pigs exposed to IA LPS needed an average of 2 days to stand and walk for the first time (45.5 and 48.6 hours, respectively; $P<0.01$, relative to CON pigs) (Figure 5, $\mathrm{K}$ and $\mathrm{L}$ ). The serum biochemical profiles showed that levels of total protein, albumin, cholesterol, liver enzymes, and phosphate were consistently lower, whereas iron and glucose levels were higher in LPS versus CON pigs on day 5, but not on day 1 (all $P<0.05$, except $P=0.06$ to $P=0.07$ for glucose and $\gamma$-glutamyl transferase) (Figure 6).

Liver and spleen from pigs euthanized at birth were all culture negative for bacteria. After 5 days of formula
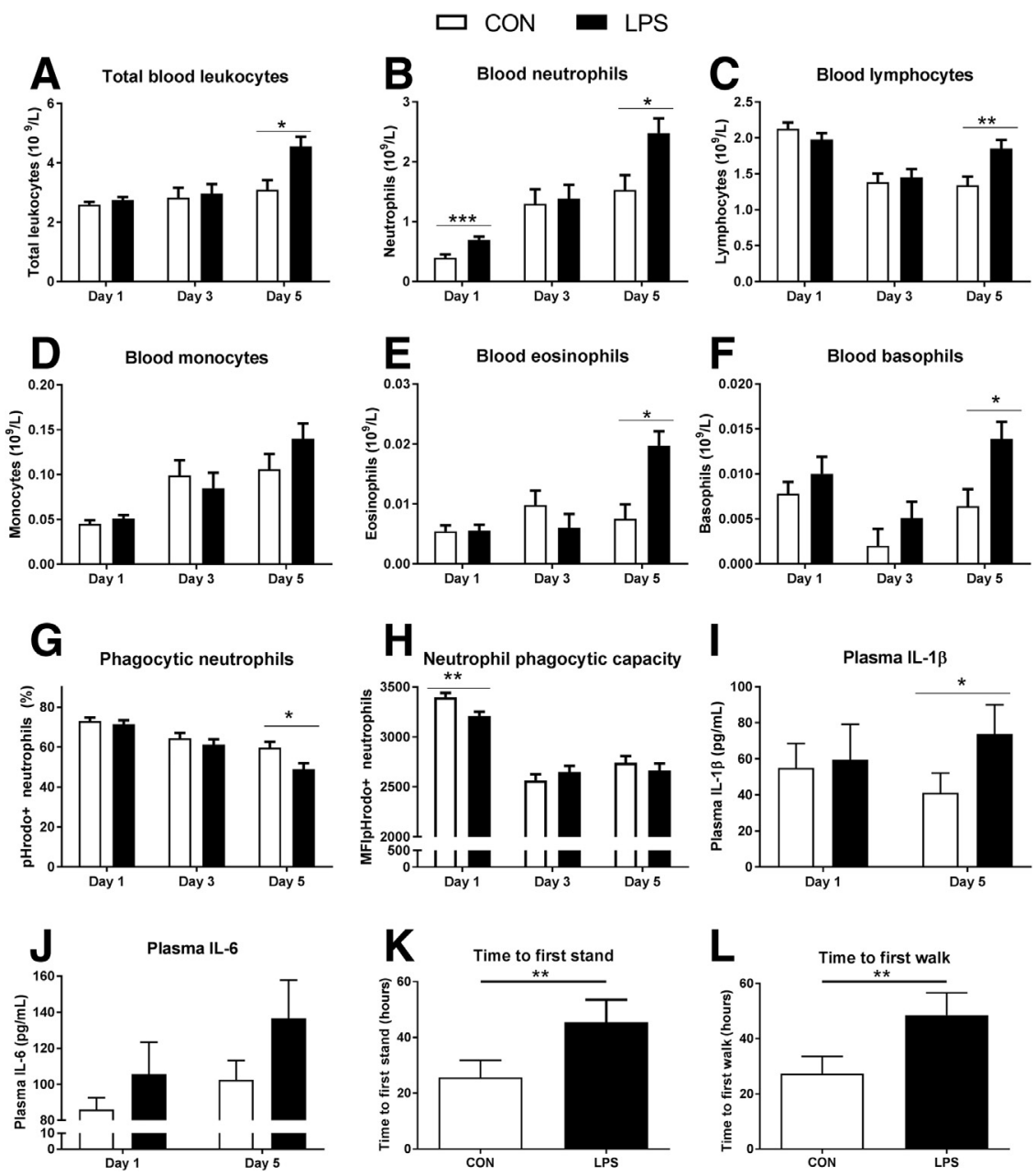

4

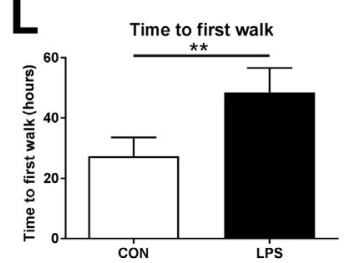

Figure 5 Intra-amniotic lipopolysaccharide (LPS) induces postnatal systemic inflammation in preterm pigs during the first 5 days of life. A-F: Hematological parameters, including total blood leukocytes (A), neutrophils (B), lymphocytes (C), monocytes (D), eosinophils (E), and basophils (F). $\mathbf{G}$ and $\mathbf{H}$ : Neutrophil phagocytosis functions, including phagocytic rate $(\mathbf{G})$ and capacity $(\mathbf{H})$. I and J: Plasma cytokines IL-1 $\beta$ (I) and IL-6 (J) at euthanasia on day 1 and day 5. $\mathbf{K}$ and $\mathbf{L}$ : Time from birth to the first observed time of standing and walking in preterm pigs receiving postnatal nutrition. Linear models with treatment, litter, and sex as fixed factors or linear mixed models with treatment, time, and litter as fixed factors and pig identification as a random factor were used for statistics. Data are expressed as means \pm SEM $(\mathbf{A}-\mathbf{L}) \cdot n=14$ to 15 per group $(\mathbf{A}-\mathbf{F}) ; n=12$ to 15 per group ( $\mathbf{G}$ and $\mathbf{H}$ ); $n=9$ to 10 day 1 ( $\mathbf{I}$ and $\mathbf{J}$ ); $n=15$ day 5 (I and $\mathbf{J}$ ) and per group ( $\mathbf{K}$ and $\mathbf{L}) .{ }^{*} P<0.05,{ }^{*} P P<0.01$, and $* * * P<0.001$. 
feeding, a numerically higher frequency of LPS pigs had bacteria detected in the spleen (but not in the liver), relative to CON pigs [7/15 (47\%) versus $3 / 13(23 \%) ; P=0.25]$ (Figure 7). Specifically, splenic counts of Staphylococcus species tended to be higher in LPS versus CON pigs $(P=0.09)$ (Figure 7). Blood neutrophil counts on day 5 were positively correlated with splenic bacterial counts $(r=0.529, P<0.01)$, and there were tendencies to higher plasma IL-6 and IL-1 $\beta$ levels in pigs with than in pigs without detected splenic bacteria $(P=0.05$ to $P=0.06)$ (Supplemental Figure S3, D-F). Collectively, data from blood and internal organ analyses indicate the systemic effects of IA LPS are more gradual, with mild fetal impacts at birth but extensive postnatal systemic inflammation on day 5 .

\section{Discussion}

Prenatal inflammation is a main risk factor for preterm birth and is associated with multiple early life complications in preterm infants, including infection and NEC. ${ }^{1,4,5}$
However, it remains elusive how prenatal inflammation influences the postnatal immune status and organ functions when preterm neonates are nourished and colonized with gut flora. Many previous studies only focused on those effects at birth or shortly after birth without enteral feeding. ${ }^{45,46}$ In the current study, we examined the postnatal effects of prenatal bacterial toxin exposure in formula-fed preterm pigs. On the basis of previous fetal lamb studies with acute LPS exposure at 0.1 to $10 \mathrm{mg} /$ fetus, ${ }^{28,47}$ the highest tolerable LPS dose that did not compromise neonatal survival $(1 \mathrm{mg} / \mathrm{pig}$ fetus with $14 \%$ fetal loss versus $0 \%$ in control fetuses, equivalent to $4 \mathrm{mg} /$ fetal lamb, because of differences in amniotic fluid volume $^{48,49}$ ) was selected. IA LPS exposure 3 days before preterm birth not only induced chorioamnionitis and fetal lung and gut inflammation, but also resulted in postnatal systemic inflammation with increased splenic bacterial accumulation and internal organ dysfunction. At this dose and time of exposure, IA LPS did not markedly affect gut structure and functions or NEC sensitivity (except tendency to more diarrhea). These findings provide novel insight into how the developing immune system and
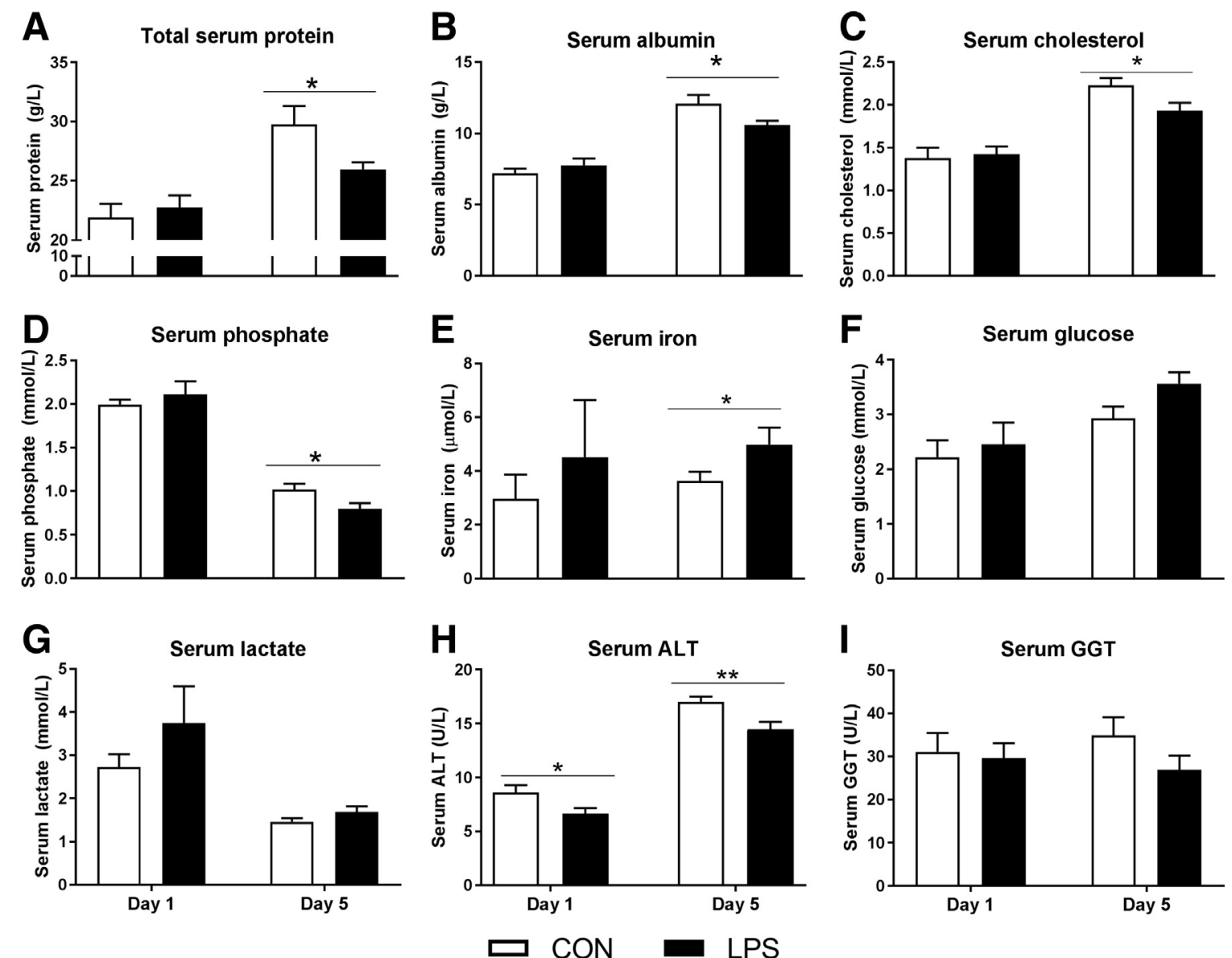

Figure 6 Effects of intra-amniotic lipopolysaccharide (LPS) on fetal and postnatal serum biochemical profiles in preterm pigs. Serum biochemical parameters, including total proteins $(\mathbf{A})$, albumin $(\mathbf{B})$, cholesterol $(\mathbf{C})$, phosphate $(\mathbf{D})$, iron $(\mathbf{E})$, glucose $(\mathbf{F})$, lactate $(\mathbf{G})$, and liver enzymes $(\mathbf{H}$ and $\mathbf{I})$. Linear models with treatment and litter as fixed factors were used for statistics. Data are expressed as means \pm SEM (A-I). $n=8$ to 11 day 1 (A-I); $n=15$ day 5 $(\mathrm{A}-\mathrm{I}) .{ }^{*} P<0.05,{ }^{*} P<0.01$. ALT, alanine aminotransferase; CON, control; GGT, $\gamma$-glutamyl transferase. 

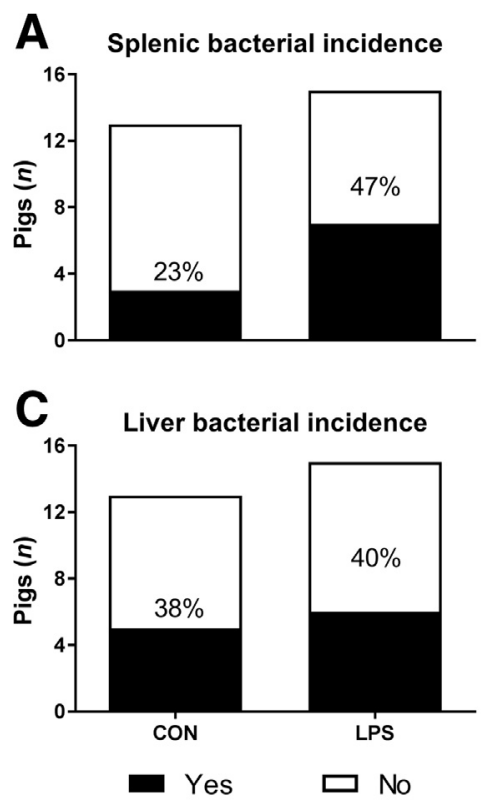
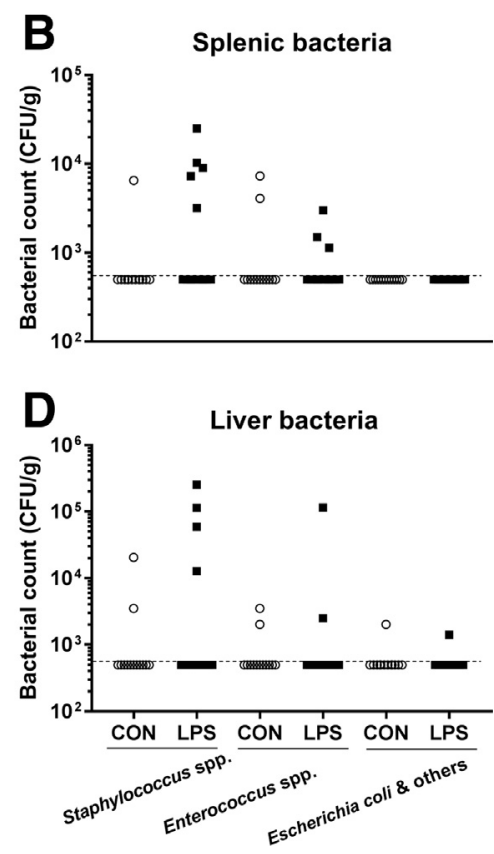

Figure 7 Intra-amniotic lipopolysaccharide (LPS) elevates organ bacterial accumulation on postnatal day 5 in preterm pigs. Incidence of bacterial detection (A and $\mathbf{C}$ ) and levels of bacterial accumulation (B and $\mathbf{D}$ ) in the spleen and liver of preterm pigs at euthanasia on day 5. A and C: Fisher exact tests were used to compare the two groups. B and D: Each mark represents an individual pig; $U$-tests were used for statistics. $n=13$ to 15 per group (A-D). CFU, colony-forming unit; CON, control; spp., species. critical organs are affected before and after preterm birth by short-term prenatal IA exposure to bacterial endotoxin.

The acute LPS effects were observed mainly in the fetal gut and lungs at birth in a similar manner, with strong elevation of tissue endotoxin, CXCL8, and IL- $1 \beta$ levels and infiltration of $\mathrm{MPO}^{+}$neutrophils/macrophages but not $\mathrm{CD}^{+}$lymphocytes and IL-6, implying the innate gut and lung inflammatory response to direct LPS exposure via amniotic fluid. In contrast, IA LPS-induced systemic changes at birth were minimal (except elevated cord blood neutrophil counts). This is consistent with lamb studies suggesting that fetal epithelial surfaces (gut, lungs, and skin) that are in contact with amniotic fluid are the first sites of inflammation elicited by IA LPS or amniotic fluid cytokines induced by IA LPS, whereas the fetal systemic effects are indirect and develop subsequently to the affected epithelial surfaces. ${ }^{17,18}$ Importantly, we found in the current study that the IA LPS-induced innate inflammatory responses in the fetal gut and lungs decreased after preterm birth, with no effects on adaptive immune parameters on day 5. This is probably because the acute responses to IA LPS at epithelial surfaces were partially cleared when the source of endotoxin exposure (amniotic fluid) was ceased at birth. These trends are in contrast with the increased systemic inflammation after birth in LPS pigs, as shown by poor neonatal arousal during the first 2 days of life and extensive systemic responses on day 5. In addition, trivial LPS levels found in the blood of the fetus at birth or in preterm pigs on postnatal day 5 again imply that the systemic effects of prenatal LPS were indirect. Taken together, our data indicate that the systemic effects of IA LPS may be indirectly initiated from the preceding local inflammation at epithelial tissues of fetal gut, lungs, and skin, and then gradually amplified over the first days after preterm birth. Suboptimal formula feeding and immature exposure to the postnatal environment with billions of antigens may also contribute to the amplification process, but further investigations are needed to confirm this speculation.

Pregnant women with IA inflammation may or may not have clinical infection symptoms or histologic chorioamnionitis. $^{26,31}$ The AF and placenta are usually not investigated in asymptomatic mothers, presumably resulting in many unnoticed cases of prenatal inflammation. Similar to previous studies with chorioamnionitis in humans ${ }^{50}$ and intra-amniotic inflammation in pigs ${ }^{19,20,51}$ and sheep, acute IA LPS exposure in our study induced a mild infiltration of inflammatory cells in the chorioamnion and elevated levels of a series of amniotic fluid cytokines without any symptoms of maternal inflammation. The IA LPS-induced fetal lung inflammation, with elevated cytokines and infiltrated $\mathrm{MPO}^{+}$cells, is also consistent with previous studies in fetal lambs ${ }^{52,53}$ and pigs. ${ }^{20}$ Direct fetal lung exposure to LPS and LPS-induced cytokines in amniotic fluid may stimulate epithelial cells and infiltrated macrophages and neutrophils to secrete CXCL8 and IL- $1 \beta,^{54,55}$ whereas no changes in IL-6 and CD3 ${ }^{+}$lymphocytes suggest that this may be an acute response with short exposure time of 3 days without major roles of lymphocytes, as shown previously in macaques. ${ }^{26}$ These acute lung responses may partially be cleared the first days after preterm birth when the lungs are switched to a new postnatal environment without further contact with elevated amniotic fluid cytokine levels, explaining the reduced levels of tissue $\mathrm{MPO}^{+}$cells, CXCL8, and IL-1 $\beta$ on day 5 . 
Similar to the lungs, the main IA LPS effects in the gut were observed at birth, with elevated levels of $\mathrm{MPO}^{+}$cell infiltration, IL-1 $\beta$, and CXCL8, and altered gene expressions (elevated ILIB,CD14, TLR2, ISG2O,C3, and CXCL9 and decreased $\mathrm{ZO1}$ ) related to innate immune responses. Like in preterm infants, no NEC lesions were observed at birth before enteral feeding, irrespective of prenatal complications. These observations were in line with studies in fetal lambs exposed to IA LPS, Ureaplasma species, or fungi, in which fetal gut inflammation was shown with increased cytokine levels and decreased barrier function. ${ }^{21-25}$ In addition, LPS-exposed pigs on both days 1 and 5 had elevated levels of gut markers related to Tregs (increased Foxp $3^{+}$cell density and $T G F B$ expression on day 1 and increased expression of FOXP3 and IL10 on day 5), suggesting a gut anti-inflammatory response in parallel with innate immune responses induced by LPS. Treg activity is regulated via production of IL-10 and transforming growth factor- $\beta$, but it is not necessarily protective because of the immune suppressive effects in the presence of pathogens. ${ }^{56}$ For instance, increased systemic Treg proportion was shown in infants with early-onset sepsis. ${ }^{57}$ On the other hand, it is possible that the Treg increase in the fetal gut after IA LPS may be related to the increased maternal microchimeric Treg migration to offspring, as previously reported. ${ }^{58}$

It remains that the short-term IA LPS exposure for 3 days did not markedly alter gut morphology, enzymes, permeability, gut absorptive functions, and NEC incidence on day 5 , the age when preterm pigs are highly sensitive to NEC. ${ }^{32}$ Normally, these gut parameters are strongly related to dietor gut microbiota-associated NEC lesions in preterm pigs. ${ }^{33-35}$ One possibility is that factors, such as the milk diet, feeding regimen, and gut microbiota, are stronger determinants of gut inflammation and NEC than prenatal inflammation. Another possibility is that the short-term exposure to IA LPS may only induce acute, but not chronic, fetal gut inflammation and the immune response was, to a large degree, cleared shortly after birth when direct contact with amniotic fluid ceased before formula feeding and gut bacterial colonization began. Thus, NEC appeared to be induced mainly by formula feeding in this study, not by the degree of prenatal inflammation. A longer-term IA exposure to inflammatory agents may exhibit more potent and persistent gut effects in both fetal and postnatal pigs, potentially leading to greater NEC sensitivity. IA LPS exposure of 7 to 30 days in fetal lambs showed more potent and chronic gut inflammatory responses with more neutrophil/macrophage infiltration and impaired barrier structure, relative to short-term exposure of 2 days. ${ }^{23,25}$ It is important to confirm in future studies whether a more long-term IA LPS exposure causes chronic gut inflammation contributing to NEC development in formula-fed pigs.

The observed mild systemic effects of IA LPS at birth were similar to those reported in earlier studies in fetal lambs and rhesus macaques after a 3-day IA exposure to LPS, Ureaplasma parvum, or IL-1 $\beta .^{26,47,59}$ In contrast, potentiated systemic responses in LPS pigs on postnatal day 5 were shown with increased blood leukocyte subsets and plasma cytokines and altered biochemical profiles. The elevated plasma IL-1 $\beta$ and IL-6 may result from increased counts and activated blood leukocytes, whereas the decreased serum albumin and cholesterol levels (relative to $\mathrm{CON}$ pigs and healthy preterm pigs ${ }^{33}$ ) may reflect an acute hepatic response to systemic inflammation. ${ }^{60,61}$ Furthermore, the consistent decreases in other serum biochemical parameters, with decreased relative kidney weight, but without elevated liver enzymes, in LPS pigs on day 5, indicate possible loss of circulatory components attributable to renal dysfunction. In the subset of NEC pigs, $\mu$-albumin/ creatinine ratio and sodium levels were elevated in LPS versus CON pigs, further supporting postnatal renal dysfunctions in response to IA LPS. These data may also explain the poorer clinical status of LPS pigs with delayed time from birth to the first signs of standing and walking. The resulting postnatal systemic inflammation in LPS pigs may cause decreased capacity to combat future infections, entering via indwelling catheters or bacteria translocated from the immature gut or lungs. This explains higher incidence of splenic bacterial accumulation (especially Staphylococcus) in LPS pigs on day 5.

In conclusion, this study demonstrated comprehensive effects of a short-term exposure to IA inflammation in both fetal and preterm newborn piglets. Although the effects on immature lungs and gut were limited beyond the newborn period, prenatal LPS exposure induced postnatal systemic inflammation, potentially starting to affect internal organs (eg, kidneys). It is important to clarify in future studies if these effects are only temporary or persist and generate long-term organ dysfunctions in preterm neonates. Our results also highlight the importance of early diagnosis of prenatal inflammation to facilitate nutritional, medical, or pharmaceutical interventions that attenuate the detrimental postnatal responses to prenatal inflammation.

\section{Acknowledgments}

We thank Karina Ryom, Pingping Jiang, Jane Poulsen, Elin Skytte, Kristina Møller, Katrine V. Kristiansen, and Manja Hanegård (University of Copenhagen), Karin Tarp (Technical University of Denmark), and Nico Kloosterboer (Maastricht University) for assistance in laboratory analyses.

D.N.N., T.T., B.W.K., T.G.W., and P.T.S. designed the study; D.N.N., T.T., S.K.G.P., and W.W. performed the animal studies; D.N.N., S.R., W.W., K.S., P.D., A.B., and C.v.G. analyzed biological samples; D.N.N. analyzed the data and drafted the manuscript; D.N.N. had full access to all of the data in the study and takes responsibility for the integrity of the data and the accuracy of data analysis; D.N.N. and P.T.S. were responsible for the final content of the article; all authors contributed to manuscript revision and accepted the final version of the manuscript. 


\section{Supplemental Data}

Supplemental material for this article can be found at https://doi.org/10.1016/j.ajpath.2018.07.020.

\section{References}

1. Strunk T, Inder T, Wang X, Burgner D, Mallard C, Levy O: Infection-induced inflammation and cerebral injury in preterm infants. Lancet Infect Dis 2014, 14:751-762

2. Goldenberg RL, Culhane JF, Iams JD, Romero R: Epidemiology and causes of preterm birth. Lancet 2008, 371:75-84

3. Kramer BW: Chorioamnionitis: new ideas from experimental models. Neonatology 2011, 99:320-325

4. Gantert M, Been JV, Gavilanes AWD, Garnier Y, Zimmermann LJI, Kramer BW: Chorioamnionitis: a multiorgan disease of the fetus? J Perinatol 2010, 30 Suppl:S21-S30

5. Korbage de Araujo MC, Schultz R, do Rosário Dias de Oliveira L, Ramos JL, Vaz FA: A risk factor for early-onset infection in premature newborns: invasion of chorioamniotic tissues by leukocytes. Early Hum Dev 1999, 56:1-15

6. Been JV, Lievense S, Zimmermann LJI, Kramer BW, Wolfs TGAM: Chorioamnionitis as a risk factor for necrotizing enterocolitis: a systematic review and meta-analysis. J Pediatr 2013, 162:236-242. e2

7. García-Muñoz Rodrigo F, Galán Henríquez G, Figueras Aloy J, García-Alix Pérez A: Outcomes of very-low-birth-weight infants exposed to maternal clinical chorioamnionitis: a multicentre study. Neonatology 2014, 106:229-234

8. Underwood MA: Human milk for the premature infant. Pediatr Clin North Am 2013, 60:189-207

9. Lucas A, Cole TJ: Breast milk and neonatal necrotising enterocolitis. Lancet 1990, 336:1519-1523

10. Schanler RJ, Shulman RJ, Lau C: Feeding strategies for premature infants: beneficial outcomes of feeding fortified human milk versus preterm formula. Pediatrics 1999, 103:1150-1157

11. Been JV, Zimmermann LJI: Histological chorioamnionitis and respiratory outcome in preterm infants. Arch Dis Child Fetal Neonatal Ed 2009, 94:F218-F225

12. Willems MGM, Ophelders DRMG, Nikiforou M, Jellema RK, Butz A, Delhaas T, Kramer BW, Wolfs TGAM: Systemic interleukin2 administration improves lung function and modulates chorioamnionitis-induced pulmonary inflammation in the ovine fetus. Am J Physiol Lung Cell Mol Physiol 2016, 310:L1-L7

13. Dean JM, Shi Z, Fleiss B, Gunn KC, Groenendaal F, van Bel F, Derrick M, Juul SE, Tan S, Gressens P, Mallard C, Bennet L, Gunn AJ: A critical review of models of perinatal infection. Dev Neurosci 2015, 37:289-304

14. Kemp MW, Saito M, Newnham JP, Nitsos I, Okamura K, Kallapur SG: Preterm birth, infection, and inflammation advances from the study of animal models. Reprod Sci 2010, 17: 619-628

15. Gisslen T, Alvarez M, Wells C, Soo M-T, Lambers DS, Knox CL, Meinzen-Derr JK, Chougnet CA, Jobe AH, Kallapur SG: Fetal inflammation associated with minimal acute morbidity in moderate/late preterm infants. Arch Dis Child Fetal Neonatal Ed 2016, [Epub ahead of print] doi:10.1136/archdischild-2015-308518

16. Schmidt AF, Kannan PS, Chougnet CA, Danzer SC, Miller LA, Jobe AH, Kallapur SG: Intra-amniotic LPS causes acute neuroinflammation in preterm rhesus macaques. J Neuroinflammation 2016, 13:238

17. Kemp MW, Kannan PS, Saito M, Newnham JP, Cox T, Jobe AH, Kramer BW, Kallapur SG: Selective exposure of the fetal lung and skin/amnion (but not gastro-intestinal tract) to LPS elicits acute systemic inflammation in fetal sheep. PLoS One 2013, 8:e63355
18. Wolfs TGAM, Kramer BW, Thuijls G, Kemp MW, Saito M, Willems MGM, Senthamarai-Kannan P, Newnham JP, Jobe AH, Kallapur SG: Chorioamnionitis-induced fetal gut injury is mediated by direct gut exposure of inflammatory mediators or by lung inflammation. Am J Physiol Gastrointest Liver Physiol 2014, 306: G382-G393

19. Trebichavský I, Splíchal I, Zahradnícková M, Splíchalová A, Mori Y: Lipopolysaccharide induces inflammatory cytokines in the pig amnion. Vet Immunol Immunopathol 2002, 87:11-18

20. Splíchal I, Trebichavský I, Splíchalová A, Dítetová L, Zahradnícková M: Escherichia coli administered into pig amniotic cavity appear in fetal airways and attract macrophages into fetal lungs. Physiol Res 2002, 51:523-528

21. Wolfs TG, Kallapur SG, Knox CL, Thuijls G, Nitsos I, Polglase GR, Collins JJP, Kroon E, Spierings J, Shroyer NF, Newnham JP, Jobe AH, Kramer BW: Antenatal ureaplasma infection impairs development of the fetal ovine gut in an IL-1-dependent manner. Mucosal Immunol 2013, 6:547-556

22. Nikiforou M, Kemp MW, van Gorp RH, Saito M, Newnham JP, Reynaert NL, Janssen LEW, Jobe AH, Kallapur SG, Kramer BW, Wolfs TGAM: Selective IL- $1 \alpha$ exposure to the fetal gut, lung, and chorioamnion/skin causes intestinal inflammatory and developmental changes in fetal sheep. Lab Invest 2016, 96:69-80

23. Nikiforou $M$, Vanderlocht $J$, Chougnet CA, Jellema RK, Ophelders DRMG, Joosten M, Kloosterboer N, SendenGijsbers BLMG, Germeraad WTV, Kramer BW, Wolfs TGAM: Prophylactic interleukin-2 treatment prevents fetal gut inflammation and injury in an ovine model of chorioamnionitis. Inflamm Bowel Dis 2015, 21:2026-2038

24. Nikiforou M, Jacobs EMR, Kemp MW, Hornef MW, Payne MS, Saito M, Newnham JP, Janssen LEW, Jobe AH, Kallapur SG, Kramer BW, Wolfs TGAM: Intra-amniotic Candida albicans infection induces mucosal injury and inflammation in the ovine fetal intestine. Sci Rep 2016, 6:29806

25. Wolfs TGAM, Buurman WA, Zoer B, Moonen RMJ, Derikx JPM, Thuijls G, Villamor E, Gantert M, Garnier Y, Zimmermann LJI, Kramer BW: Endotoxin induced chorioamnionitis prevents intestinal development during gestation in fetal sheep. PLoS One 2009, 4: e5837

26. Senthamaraikannan $P$, Presicce $P$, Rueda CM, Maneenil G, Schmidt AF, Miller LA, Waites KB, Jobe AH, Kallapur SG, Chougnet CA: Intra-amniotic Ureaplasma parvum-induced maternal and fetal inflammation and immune responses in rhesus macaques. J Infect Dis 2016, 214:1597-1604

27. Rueda CM, Presicce P, Jackson CM, Miller LA, Kallapur SG Jobe AH, Chougnet CA: Lipopolysaccharide-induced chorioamnionitis promotes IL-1-dependent inflammatory FOXP3 + CD4+ T cells in the fetal rhesus macaque. J Immunol 2016, 196:3706-3715

28. Kramer BW, Ikegami M, Moss TJM, Nitsos I, Newnham JP, Jobe AH: Endotoxin-induced chorioamnionitis modulates innate immunity of monocytes in preterm sheep. Am J Respir Crit Care Med 2005, 171:73-77

29. Azizia M, Lloyd J, Allen M, Klein N, Peebles D: Immune status in very preterm neonates. Pediatrics 2012, 129:e967-e974

30. Wolfs TGAM, Jellema RK, Turrisi G, Becucci E, Buonocore G, Kramer BW: Inflammation-induced immune suppression of the fetus: a potential link between chorioamnionitis and postnatal early onset sepsis. J Matern Fetal Neonatal Med 2012, 25 Suppl 1:8-11

31. Sweeney EL, Dando SJ, Kallapur SG, Knox CL: The human Ureaplasma species as causative agents of chorioamnionitis. Clin Microbiol Rev 2017, 30:349-379

32. Sangild PT, Thymann T, Schmidt M, Stoll B, Burrin DG, Buddington RK: Invited review: the preterm pig as a model in pediatric gastroenterology. J Anim Sci 2013, 91:4713-4729

33. Shen RL, Thymann T, Østergaard MV, Støy ACF, Krych Ł, Nielsen DS, Lauridsen C, Hartmann B, Holst JJ, Burrin DG, Sangild PT: Early gradual feeding with bovine colostrum improves 
gut function and NEC resistance relative to infant formula in preterm pigs. Am J Physiol Gastrointest Liver Physiol 2015, 309: G310-G323

34. Jensen ML, Thymann T, Cilieborg MS, Lykke M, Mølbak L, Jensen BB, Schmidt M, Kelly D, Mulder I, Burrin DG, Sangild PT: Antibiotics modulate intestinal immunity and prevent necrotizing enterocolitis in preterm neonatal piglets. Am J Physiol Gastrointest Liver Physiol 2014, 306:G59-G71

35. Birck MM, Nguyen DN, Cilieborg MS, Kamal SS, Nielsen DS, Damborg P, Olsen JE, Lauridsen C, Sangild PT, Thymann T: Enteral but not parenteral antibiotics enhance gut function and prevent necrotizing enterocolitis in formula-fed newborn preterm pigs. Am J Physiol Gastrointest Liver Physiol 2016, 310:G323-G333

36. Andersen AD, Sangild PT, Munch SL, van der Beek EM, Renes IB, Van Ginneken C, Greisen GO, Thymann T: Delayed growth, motor function and learning in preterm pigs during early postnatal life. Am J Physiol Regul Integr Comp Physiol 2016, 310:R481-R492

37. Nguyen DN, Jiang P, Frøkiær H, Heegaard PMH, Thymann T, Sangild PT: Delayed development of systemic immunity in preterm pigs as a model for preterm infants. Sci Rep 2016, 6:36816

38. Nguyen DN, Fuglsang E, Jiang P, Birck MM, Pan X, Kamal SB, Pors SE, Gammelgaard PL, Nielsen DS, Thymann T, Levy O, Frøkiær H, Sangild PT: Oral antibiotics increase blood neutrophil maturation and reduce bacteremia and necrotizing enterocolitis in the immediate postnatal period of preterm pigs. Innate Immun 2016, 22: $51-62$

39. Redline RW, Faye-Petersen O, Heller D, Qureshi F, Savell V, Vogler C; Society for Pediatric Pathology, Perinatal Section, Amniotic Fluid Infection Nosology Committee: Amniotic infection syndrome: nosology and reproducibility of placental reaction patterns. Pediatr Dev Pathol 2003, 6:435-448

40. Snyder CC, Wolfe KB, Gisslen T, Knox CL, Kemp MW, Kramer BW, Newnham JP, Jobe AH, Kallapur SG: Modulation of lipopolysaccharide-induced chorioamnionitis by Ureaplasma parvum in sheep. Am J Obstet Gynecol 2013, 208:399.e1-399.e8

41. Barington K, Jensen HE, Skovgaard K: Forensic aspects of gene expression signatures for age determination in bruises as evaluated in an experimental porcine model. Forensic Sci Med Pathol 2017, 13: $151-160$

42. Vandesompele J, De Preter K, Pattyn F, Poppe B, Van Roy N, De Paepe A, Speleman F: Accurate normalization of real-time quantitative RT-PCR data by geometric averaging of multiple internal control genes. Genome Biol 2002, 3:RESEARCH0034

43. Andersen CL, Jensen JL, Ørntoft TF: Normalization of real-time quantitative reverse transcription-PCR data: a model-based variance estimation approach to identify genes suited for normalization, applied to bladder and colon cancer data sets. Cancer Res 2004, 64: $5245-5250$

44. Nádházi Z, Takáts A, Offenmüller K, Bertók L: Plasma endotoxin level of healthy donors. Acta Microbiol Immunol Hung 2002, 49: $151-157$

45. Hanita T, Matsuda T, Saito M, Kitanishi R, Cho K, Harding R, Kobayashi Y: Potential role of prenatal inflammation in the impairment of lung development following mechanical ventilation of preterm lambs. Reprod Sci 2017, 24:478-487
46. Seehase M, Collins JJP, Kuypers E, Jellema RK, Ophelders DRMG, Ospina OL, Perez-Gil J, Bianco F, Garzia R, Razzetti R, Kramer BW: New surfactant with SP-B and C analogs gives survival benefit after inactivation in preterm lambs. PLoS One 2012, 7:e47631

47. Kramer BW, Moss TJ, Willet KE, Newnham JP, Sly PD, Kallapur SG, Ikegami M, Jobe AH: Dose and time response after intraamniotic endotoxin in preterm lambs. Am J Respir Crit Care Med 2001, 164:982-988

48. McCance RA, Dickerson JWT: The composition and origin of the foetal fluids of the pig. Development 1957, 5:43-50

49. Tomoda S, Brace RA, Longo LD: Amniotic fluid volume and fetal swallowing rate in sheep. Am J Physiol 1985, 249:R133-R138

50. Kallapur SG, Presicce P, Rueda CM, Jobe AH, Chougnet CA: Fetal immune response to chorioamnionitis. Semin Reprod Med 2014, 32: $56-67$

51. Šplíchalová A, Šplíchal I, Trebichavský I, Hojná H: Expression of inflammatory markers in pig amnion after intraamniotic infection with nonpathogenic or enteropathogenic Escherichia coli. Folia Microbiol 2004, 49:751-756

52. Jobe AH, Newnham JP, Willet KE, Moss TJ, Gore Ervin M, Padbury JF, Sly P, Ikegami M: Endotoxin-induced lung maturation in preterm lambs is not mediated by cortisol. Am J Respir Crit Care Med 2000, 162:1656-1661

53. Kallapur SG, Moss TJM, Ikegami M, Jasman RL, Newnham JP, Jobe AH: Recruited inflammatory cells mediate endotoxin-induced lung maturation in preterm fetal lambs. Am J Respir Crit Care Med $2005,172: 1315-1321$

54. Kallapur SG, Willet KE, Jobe AH, Ikegami M, Bachurski CJ: Intraamniotic endotoxin: chorioamnionitis precedes lung maturation in preterm lambs. Am J Physiol Lung Cell Mol Physiol 2001, 280: L527-L536

55. Maneenil G, Kemp MW, Kannan PS, Kramer BW, Saito M, Newnham JP, Jobe AH, Kallapur SG: Oral, nasal and pharyngeal exposure to lipopolysaccharide causes a fetal inflammatory response in sheep. PLoS One 2015, 10:e0119281

56. Levings MK, Bacchetta R, Schulz U, Roncarolo MG: The role of IL10 and TGF-beta in the differentiation and effector function of $\mathrm{T}$ regulatory cells. Int Arch Allergy Immunol 2002, 129:263-276

57. Pagel J, Hartz A, Figge J, Gille C, Eschweiler S, Petersen K, Schreiter L, Hammer J, Karsten CM, Friedrich D, Herting E, Göpel W, Rupp J, Härtel C: Regulatory $\mathrm{T}$ cell frequencies are increased in preterm infants with clinical early-onset sepsis. Clin Exp Immunol 2016, 185:219-227

58. Kinder JM, Jiang TT, Ertelt JM, Xin L, Strong BS, Shaaban AF, Way SS: Cross-generational reproductive fitness enforced by microchimeric maternal cells. Cell 2015, 162:505-515

59. Kallapur SG, Presicce P, Senthamaraikannan P, Alvarez M, Tarantal AF, Miller LM, Jobe AH, Chougnet CA: Intra-amniotic $\mathrm{IL}-1 \beta$ induces fetal inflammation in rhesus monkeys and alters the regulatory T cel1/IL-17 balance. J Immunol 2013, 191:1102-1109

60. Gabay C, Kushner I: Acute-phase proteins and other systemic responses to inflammation. N Engl J Med 1999, 340:448-454

61. Chien J-Y, Jerng J-S, Yu C-J, Yang P-C: Low serum level of highdensity lipoprotein cholesterol is a poor prognostic factor for severe sepsis. Crit Care Med 2005, 33:1688-1693 